\title{
MELHORANDO O PROCESSO DE ENSINO E APRENDIZADO EM CURSOS DE GRADUAÇÃO NA ÁREA DE COMPUTAÇÃO POR MEIO DA UTILIZAÇÃO DE EDUBLOGS
}

\author{
Alberto Sampaio LIMA ${ }^{1}$ \\ Wagner Bandeira ANDRIOLA ${ }^{2}$ \\ Wladimir Araújo TAVARES ${ }^{3}$
}

RESUMO: A utilização de blogs como ferramenta pedagógica de apoio ao processo de ensino e aprendizado tem sido temática debatida pelos pesquisadores na área de educação. Esse trabalho apresenta um estudo sobre a utilização dos blogs como instrumento mediador do processo de ensino e aprendizado em cursos de graduação na área de computação. Foram avaliados três blogs utilizados por alunos em cursos de graduação da Universidade Federal do Ceará (UFC). Avaliou-se os problemas e os cenários de sucesso, onde o emprego desta ferramenta pedagógica proporcionou aumento da motivação dos alunos, melhoria no processo de comunicação entre os atores envolvidos, gerando melhores resultados de aprendizagem dos alunos e melhores avaliações do ensino dos professores.

PALAVRAS-CHAVE: Edublogs. Ensino-aprendizagem. Práticas pedagógicas.

\section{INTRODUÇÃO}

A aprendizagem consiste no processo através do qual os conhecimentos, as habilidades, as competências, o comportamento ou os valores são adquiridos ou modificados. O aprendizado é resultado de estudo, experiência, formação, raciocínio e observação, podendo ser analisado a partir de diferentes perspectivas. Dessa forma, existem diferentes teorias sobre a aprendizagem. Além de ser uma das funções mentais mais importantes em humanos e animais, a aprendizagem ainda pode ser aplicada a sistemas computacionais. O estudo da aprendizagem utiliza os conhecimentos e teorias da neuropsicologia, psicologia, educação e pedagogia. Ao se abordar ensino e aprendizado há que se deixar claro que o segundo termo do binômio influencia o primeiro, ou seja, as concepções docentes do que seja aprendizado condicionarão as estratégias de ensino adotadas.

De acordo com Ferracioli (1999), o construtivismo aprofundou a questão sobre o que é desenvolvimento, como se dá a construção do conhecimento pelo sujeito e do significado de aprendizagem, além de mostrar que a articulação destes aspectos pode

\footnotetext{
1 UFC - Universidade Federal do Ceará Campus Quixadá. Pesquisador nas áreas de Educação e Computação. Quixadá - CE - Brasil. 63900-000 - albertosampaio@ufc.br

${ }^{2}$ Bolsista de produtividade em pesquisa do CNPq (Nível 1D). Coordenador de Avaliação Institucional. UFC - Universidade Federal do Ceará. Pró-Reitoria de Planejamento. Fortaleza - CE - Brasil. 60020-180 -w_andriola@ufc.br

${ }^{3}$ Doutorando em Ciência da Computação. Centro de Ciências. Fortaleza - CE - Brasil. 60455-760 wladimirufc@gmail.com
} 
estabelecer diretrizes para a investigação do processo de ensino e aprendizagem. $\mathrm{O}$ autor ainda afirmou que o conceito de aprendizagem ligada à aquisição de um conhecimento novo e específico derivado do meio, além de ser um processo limitado a um problema único ou a uma estrutura única, é diferenciado do desenvolvimento da inteligência, que corresponderia à totalidade das estruturas de conhecimento construídas.

A utilização da tecnologia da informação e comunicação (TIC) como ferramenta auxiliar no processo de ensino tem sido uma estratégia efetiva, que a cada dia tem ganhado mais espaço no meio acadêmico. Sáez (2012) cita que o papel do professor é a chave para uma implementação bem sucedida sobre o uso da TIC no processo de ensino e aprendizagem. $\mathrm{O}$ autor afirma que se deve buscar um feedback em relação ao uso da TIC, e na prática a ser desenvolvida no processo de aprendizagem. As tecnologias podem gerar grandes possibilidades para impulsionar a aprendizagem construtivista e melhorar os processos de ensino e aprendizagem. Segundo Sáez (2012), as novas tecnologias são, potencialmente, veículos para a mudança e inovação. Em particular, essas tecnologias podem incentivar o aluno a abandonar a escuta passiva em favor de uma participação mais sensível. Também ajudam a trazer o mundo exterior à escola e, em geral, mudam as estratégias de educação. $\mathrm{O}$ autor afirma que a mera presença de TIC não é suficiente, existindo evidências de que a TIC aparenta ter tido pouco impacto sobre os métodos tradicionais de ensino nas escolas. Dessa forma, torna-se necessário que os professores busquem o desenvolvimento de estratégias diferenciadas quando da utilização de TIC para dar suporte ao processo de ensino e aprendizagem. Considerouse nesta pesquisa que os edublogs poderiam ser uma estratégia viável e efetiva que pudesse ajudar aos professores no desafio de fazer um bom uso das novas tecnologias, dando suporte ao processo de ensino e aprendizagem.

\section{REVISÃO DE LITERATURA E TRABALHOS RELACIONADOS}

Conforme asseverou Andriola (2004), as concepções de aprendizagem têm sofrido várias modificações ao longo do tempo. De acordo com Puentes Ferreras (1998), é possível organizar essa evolução de concepções em três grupos:

I. Aprendizado como aquisição de respostas: expressa a visão de muitos autores comportamentalistas (behavioristas). Está presente no condicionamento clássico de Ivan P. Pavlov no condicionamento instrumental de Edward L. Thorndike, bem como no condicionamento operante de Burrhus F. Skinner que advoga o 
caráter determinista do comportamento humano, condicionado pelas consequências derivadas do mesmo. Trata-se de uma ideia de aprendizagem associacionista, mecânica e determinada. Nesta perspectiva, o aluno é sujeito passivo e o professor um exímio conhecedor de estímulos ambientais (eliciadores, reforçadores, discriminativos, primários, secundários, generalizados, contínuos e intermitentes) e de reforços (positivos, negativos e aversivos), que devem ser utilizados na consecução de uma resposta de tipo instrumental (observável publicamente), empregando-se recompensa, castigo, esquiva, etc. $\mathrm{O}$ ensino-aprendizado é reduzido a uma concepção que defende (i) o aprendizado como sendo resultante de conexões entre estímulos ambientais e respostas observáveis; (ii) o modelo instrumental, na medida em que o aluno aprende um comportamento que é instrumento para alcançar uma recompensa; (iii) a concepção ambientalista, na qual a conduta é diretamente observável e controlável através de programa de estímulos e reforços (RAMOS, 1999).

II. Aprendizado como aquisição de conhecimentos: tem como marco inicial as investigações sobre a aprendizagem animal, desembocando nas investigações sobre mapas cognitivos com sujeitos humanos (STERNBERG; GRIGORENKO, 2003). Centra-se no estudo dos processos mentais, isto é, nos mecanismos cognitivos subjacentes (ou causas) ao comportamento humano, dando pouca importância aos elementos externos ao organismo. Nesse período, surgiu a clássica metáfora "mente-computador", bem como o interesse por estudar a chamada "caixa-negra" (o cérebro), que durante tanto tempo os comportamentalistas haviam deixado em segundo plano, frente a relevância dada aos inputs e outputs (elementos internos e externos ao organismo). Desde essa perspectiva, o aprendizado e o comportamento surgem de uma interação com o ambiente, não como resultado ou resposta a simples estímulos, senão como conexões entre estruturas mentais chamadas esquemas. A realidade cognitiva do organismo é posta em evidência, isto é, o sujeito adquire conhecimentos, armazena e processa informação, conduzindo ao aprendizado. O processo de ensino-aprendizagem se centra no processamento de informação (RAMOS, 2000; POZO, 2002).

III. Aprendizado como construção de significados: coincide com o período de maturidade da Psicologia Cognitiva, cujos frutos são coletados atualmente. Entre as suas diversas subáreas encontram-se algumas conhecidas, tais como: o construtivismo, a significação e a modificação cognitiva. Os investigadores dessas novas áreas supõem o aprendiz como sujeito ativo, autônomo, que pouco a pouco pode conhecer os seus próprios processos cognitivos (estilos de aprendizagem), conforme a opinião de S. Lins (2000) e Mishne (1999). Nessa perspectiva, o aluno já não se limita a adquirir conhecimentos, senão que o constrói usando a experiência para compreender e modelar o novo. A palavra mágica dessa última concepção é aprender a aprender (ANDRIOLA, 2003, 2012).

A evolução das concepções acerca do aprendizado humano possibilitou a formulação de uma definição bastante conhecida pelos Psicólogos, que é apresentada por Howe (1999). Trata-se de uma definição eminentemente cognitivista: 
Es útil considerar el aprendizaje como un término amplio, que se refiere no sólo a una única de actividad, sino a toda una familia de procesos y de hechos mentales que, de una u otra manera, permiten incrementar el conocimiento o aumentar las habilidades $y$ capacidades (HOWE, 1999, p.22).

Segundo Howe (1999), três princípios elementares fundamentam o aprendizado, e devem ser considerados pelo professor:

- Processamento mental ativo: afirma que o aprendiz deve ter um papel relevante e dinâmico no processo de ensino-aprendizado. Deve ser um sujeito ativo, já que a eficácia do processo pode ser muito maior se os aprendizes estiverem envolvidos com as tarefas ou as atividades pedagógicas, isto é, se estão motivados a aprender através da interação.

- Estabelecimento de relações significativas: é caracterizada pelo estabelecimento de vínculos entre os elementos aprendidos recentemente; pelas relações entre o material recém aprendido e as antigas informações que o aprendiz já conhecia. Tais características supõem a adoção de um papel ativo por parte do aprendiz, isto é, o sujeito é o principal responsável pela associação entre os conteúdos aprendidos, através da execução de inúmeros procedimentos: novas leituras, consultas bibliográficas, pesquisas documentais e de campo, execução de experimentos, análise e síntese de dados, revisão sistemática do conteúdo, etc.

- Repetição sistemática: destaca-se a revisão de conteúdos (cujos componentes são majoritariamente cognitivos, p. ex. aprendizado da matemática) e a repetição de uma prática (cujos componentes são majoritariamente físicos, p. ex. aprendizado da natação e da música). Em muitas ocasiões mesclam-se ambos os tipos (p. ex. o aprendizado do xadrez).

Os três princípios propostos por Howe (1999) podem ser potencializados no ambiente escolar, apesar de haver um grande desafio para os professores: organizar $o$ conteúdo didático de modo que os seus alunos incrementem esses aspectos (ANDERSON, 1995; HOWE, 1985). No entanto, outro problema com o qual se deparam os docentes reside em responder a outra indagação: é possível aprimorar $o$ aprendizado do alunado com a utilização de ferramentas tecnológicas?

Dentre as propostas que tratam do aprendizado com base na construção de significados, a abordagem construtivista tem sido utilizada com sucesso em trabalhos onde as tecnologias da informação e comunicação (TICs), fornecendo suporte efetivo ao processo de ensino e aprendizado. A motivação deste trabalho surgiu a partir da hipótese de que os edublogs seriam ferramentas de TIC com potencial para uso efetivo no processo de ensino e aprendizagem em uma abordagem construtivista. 
O aprimoramento do ensino e aprendizado foi foco do trabalho de Silva, Silva e Maiochi (2012), que avaliou a utilização de um blog nas séries de alfabetização, por meio de um projeto aplicado na primeira série do ensino fundamental. Os avanços dessa turma de alfabetização, mediados pelo uso do blog, foram comparados aos de outra em que o projeto não foi aplicado, onde os resultados superaram as expectativas. Os resultados apresentados nessa pesquisa reforçaram nossa hipótese de que o instrumento seria útil para uma abordagem para o ensino superior.

Já a pesquisa realizada por Borba e Thomazi (2012), mostrou que as TICs poderiam ser utilizadas para melhoria do processo de ensino e aprendizagem em escolas destinadas ao ensino superior na área de computação. $\mathrm{O}$ estudo teve o objetivo de compreender as relações existentes entre a tecnologia, o educador e o educando, no processo de ensino-aprendizagem das disciplinas técnicas junto a um grupo de alunos de um curso de graduação tecnológica em Análise e Desenvolvimento de Sistemas. Dando continuidade ao aspecto de avaliação das novas tecnologias no processo ensinoaprendizagem, pode-se citar o trabalho de Barro e Queiroz (2012), onde os autores analisaram a utilização e aceitação de blogs em uma disciplina de comunicação científica oferecida em um curso superior de química. Foram realizadas na disciplina atividades com artigos científicos e atividades de resolução de casos investigativos com a utilização de blog. Os alunos publicaram nos blogs as suas atividades extraclasse, reflexões e comentários, com a ocorrência de comentários de alunos, da professora e do estagiário, enriquecendo o processo de interação. Os resultados indicaram uma postura favorável dos estudantes frente à utilização dos blogs como ferramentas de apoio ao processo de ensino e aprendizagem.

A experiência docente com o uso das TICs foi abordada por Molins e Raabe (2012), onde os autores apresentaram os resultados de uma pesquisa que investigou as percepções de um grupo de professores sobre possíveis transformações ocorridas em suas práticas pedagógicas após terem participado de um curso de formação continuada denominado "Introdução à Educação Digital". Os resultados indicaram que os professores mudaram sua prática pedagógica, com incremento no uso técnicopedagógico do computador e introdução dos recursos mais avançados. Entretanto, a pesquisa revelou que o número de professores que usam o computador nas atividades com os alunos é ainda pequeno e este uso restringe-se aos laboratórios de Informática das escolas. Entre os resultados apresentados, os autores destacaram que após o curso os ambientes virtuais foram integrados à prática pedagógica, como o uso do blog e do 
correio eletrônico às atividades com os alunos. Os autores afirmaram que essa informação parece revelar que os docentes acordaram para a necessidade de inserir na prática pedagógica ferramentas que ajudam a aproximar pessoas, a distribuir o conhecimento e a incentivar a aprendizagem colaborativa; que o blog pode ser utilizado como um laboratório de escrita virtual e os blogueiros podem agir, interagir e trocar experiências, difundir projetos desenvolvidos na escola, além de ter acesso a informações atualizadas.

A utilização de blogs como ferramenta de suporte ao processo de ensino e aprendizagem também foi abordada no trabalho de Mazocatto e Krug (2012), onde os autores afirmaram que existe um desafio para o ambiente escolar no sentido de inovar, interligando os recursos tecnológicos para a promoção de uma nova realidade educacional, projetando-se a construção de um ensino de qualidade a partir de novas tecnologias. Os autores buscaram discutir a utilização de um blog como forma de acesso à informação e ao ensino através da internet. Os resultados de um estudo de caso indicaram que o blog teve o papel de facilitador no processo de aprendizagem, cumprindo o seu objetivo, qual seja, aproximar as novas tecnologias, o diálogo, os questionamentos, a reflexão, a interlocução dos saberes, com os participantes do blog.

Os blogs também foram avaliados em sua possível contribuição para o processo de ensino e aprendizagem em função do seu potencial de comunicação. No âmbito corporativo, pode-se citar o trabalho de Tassigny et al. (2012), onde se buscou debater a importância do blog como ferramenta da comunicação organizacional interna e externa, destacando-o como uma nova modalidade de comunicação que pode colaborar no gerenciamento de informações e na construção de uma imagem empresarial competitiva, motivando o público interno e fidelizando clientes. Os resultados indicaram que os blogs organizacionais constituem instrumentos com poder de comunicação bidirecional instantâneo, aptos a assegurarem uma interação de informações entre a organização e seus públicos, constituindo-se uma estratégia no fortalecimento da imagem frente ao público alvo, funcionando como ferramenta colaborativa de gestão da informação.

A utilização de blogs como ferramenta de suporte ao processo de ensino e aprendizagem pode ocasionar uma mudança nos paradigmas atuais de educação. Segundo Garcia-Sabater et al. (2012) existe um grande potencial do blog como ferramenta docente facilitadora para uma mudança dos sistemas tradicionais de educação. Em primeiro lugar, sua utilização fomenta a aprendizagem ativa, autônoma e 
reflexiva. Em segundo lugar, apresenta uma alta versatilidade de uso, tanto na docência presencial quanto à distância. Em terceiro lugar, seu custo é mínimo, tanto para os docentes quanto para os estudantes. Ressalta o autor que os edublogs, assim como qualquer nova tecnologia, não garantem uma maior eficácia educativa simplesmente por sua utilização. O resultado depende do enfoque, dos objetivos e da metodologia de integração em cada programa educativo. O autor ainda afirma é possível se desenvolver habilidades e competências no aluno, a partir de sua experiência como autor de um blog. Deve haver o aproveitamento de todas as possibilidades de uso dos blogs, tal como o formato de publicação e o uso de um instrumento para a interação social na rede. Entre as principais vantagens identificadas no trabalho destacaram-se: os blogs ajudam aos alunos a se tornarem especialistas; aumentam o interesse dos estudantes na aprendizagem; proporcionam a participação, oferecendo novas perspectivas dentro e fora da sala de aula.

Já Fiedler e Wrede (2004 apud GARCIA-SABATER et al., 2012), destacaram o potencial dos weblogs como ferramenta para facilitar o diálogo e o discurso acadêmico. Tal assertiva é reforçada pela citação de Pérez (2012), o qual afirma que os professores podem utilizar os blogs com o objetivo de criar uma forma nova e atrativa de se relacionar com os estudantes, sem limitar a sua interação exclusivamente à aula. É possível a publicação de materiais, permitindo o acesso à informação e a recursos necessários para se realizar projetos e atividades de aula, otimizando dessa forma o tempo de aula.

Os blogs ainda têm sido utilizados como ferramentas de suporte ao processo de ensino e aprendizagem em várias áreas de formação. A utilização de novas tecnologias na pesquisa e na formação inicial de professoras de educação infantil foi abordada por Marques e Müller (2012). Os autores apresentam o percurso para a escolha e utilização do blog como instrumento de registro e documentação dos dados durante o período de estágio supervisionado na educação infantil, onde os resultados indicaram que a utilização do blog favoreceu a aprendizagem de aspectos essenciais e mostrou-se uma ferramenta importante para a formação inicial de professoras. Foi citado por Bento, Miguel e Alexandre (2012), que a utilização da tecnologia como ferramenta pedagógica para o uso da própria formação não é prática comum. Os autores procederam um estudo sobre o blog "Pedagogos blogando", destinado a formação continuada de pedagogos. Afirmou-se que o blog é considerado como vitrine e a interação no mesmo um enfrentamento necessário. 
Yang (2009) avaliou a utilização de blogs no processo de treinamento da língua inglesa como uma língua estrangeira para professores que estavam aprendendo a ensinar. O blog foi analisado como plataforma de aprendizagem e avaliou-se ainda o impacto do mesmo no crescimento profissional dos professores de língua estrangeira. $\mathrm{O}$ blog foi utilizado pelos participantes como um espaço de discussão, como um fórum que preparou cada um dos professores-alunos a relacionar teorias para praticar discutindo crenças, aprendendo uns com os outros, demonstrando um ao outro como agiriam em suas salas de aula reais. A utilização dos blogs ofereceu mais flexibilidade de tempo e espaço para os professores-alunos refletirem e discutirem.

Em H. Lins (2011), foram apresentadas algumas concepções sobre os conceitos de blog, assim como o papel das novas tecnologias na sociedade e na educação, numa perspectiva voltada aos impactos das mesmas na cultura e nas mentalidades e sua caracterização como um importante instrumento pedagógico e político nos processos de ensino e aprendizagem.

Conforme Williams e Jacobs (2012), os blogs podem proporcionar um fórum para o discurso acadêmico que ultrapassa o âmbito de uma disciplina universitária e aumenta a criação de conhecimento por parte do aluno. No estudo realizado, foi verificado que os estudantes aprenderam muito uns com os outros, bem mais do que com um instrutor ou livro. Foi necessária apenas a identificação de um meio para facilitar todo o processo, no caso o blog. Os autores consideraram que a utilização de blogs não irá substituir o ensino presencial em sala de aula, mas complementar o processo.

O material didático a informação a ser disponibilizada nos blogs que fornecem suporte ao processo de ensino e aprendizagem também foi objeto de estudo nas pesquisas recentes. De Barros (2012) afirmou que o processo de estruturação de um material didático deve ser dinâmico, resultando de discussões e avaliações contínuas estabelecidas por uma comunidade acadêmica. $\mathrm{O}$ autor afirma que um saber se constitui a partir de quatro elementos fundamentais: problemas, técnicas (maneiras de resolver os problemas), tecnologias (discursos racionais sobre as técnicas) e teorias (justificativa, explicação e produção de tecnologias). Em seu trabalho, a estruturação dos materiais didáticos observou os níveis de granularidade, caracterizando-se metadados e exercitou a disponibilização dos materiais em um blog, especificamente em uma área destinada para objetos de aprendizagem dirigidos ao ensino/aprendizagem. 
A partir do contexto apresentado nesta revisão de literatura, a presente pesquisa envolveu um estudo sobre a utilização dos blogs como instrumento mediador do processo de ensino e aprendizado em cursos de graduação da área de computação. Através da análise dos resultados de três casos que avaliaram os blogs utilizados pelos alunos dos cursos de Sistemas de Informação, Engenharia de Software e Redes de Computadores da Universidade Federal do Ceará (UFC), buscou-se apresentar algumas problemáticas específicas e os cenários de sucesso da utilização de blogs.

\section{MÉTODO DE PESQUISA}

Face à natureza da investigação avaliativa, que aborda as opiniões de discentes acerca da atuação dos seus professores no uso dos blogs como ferramenta de melhoria do processo ensino-aprendizagem, empregou-se o método ex post-facto, conforme apregoa Alzina (2004), também conhecido como método estatístico (GIL, 1999) ou método correlacional (KERLINGER apud LEE, 2002).

Para avaliar o impacto do uso dos blogs junto aos estudantes, foram realizadas entrevistas semiestruturadas com a participação de 75 alunos envolvidos nos três estudos de caso. As disciplinas que estiveram suportadas pelos blogs neste estudo foram governança estratégica de TI, gestão de sistemas de informação, linguagens de programação e ética na computação.

Os dados obtidos a partir das entrevistas e da observação dos pesquisadores foram tabulados, analisados e confrontados com as informações obtidas na revisão de literatura.

\section{POPULAÇÕES E AMOSTRAS}

As populações-alvo da pesquisa foram constituídas pelos dois docentes que ministraram disciplinas que utilizaram os blogs durante a pesquisa, pelos três alunos que participaram da edição dos blogs junto com os professores e pelos discentes usuários dos blogs.

A amostra de discentes que avaliou o blog Simplificando a Governança de TI foi formada por 51 alunos matriculados em disciplinas na área de gestão de TI ofertadas pelos cursos de Sistemas de Informação e Redes de Computadores da UFC, que participaram de entrevista específica sobre o impacto da utilização dos blogs nas disciplinas. Na avaliação do blog Marathon Code, a amostra constituiu-se de 14 alunos que utilizam regularmente a ferramenta em suas atividades cotidianas e cursaram 
disciplinas da área de programação. Uma amostra de 10 alunos foi utilizada na avaliação do blog Papo de Aluno.

É importante se ressaltar a dificuldade encontrada pelos pesquisadores em se reunir com cada aluno ou grupo de alunos para execução das entrevistas, por conta de limitações de tempo, agenda de provas, grande quantidade de perguntas subjetivas e objetivas nas entrevistas, entre outros fatores restritivos.

De forma complementar aos resultados das entrevistas, ainda foram mantidas conversas pessoais com estudantes, professores e demais atores do processo de uso dos blogs no campus da UFC em Quixadá durante o decorrer do ano de 2012 e início de 2013, onde foram abordados assuntos específicos através de conversas informais e mais rápidas, sempre visando a identificação impactos positivos ou negativos a partir da utilização dos blogs avaliados. Foram mantidas conversas visando o levantamento de aspectos relacionados à utilização dos blogs com 34 atores do processo durante o ano de 2012.

Dessa forma, pode-se afirmar que o estudo apresentado neste trabalho envolveu 75 entrevistados, alunos de disciplinas que usavam os blogs, 34 atores, ou seja, alunos que acessavam e liam os blogs periodicamente, os quais participaram de reuniões para discussão sobre a utilização dos blogs, três alunos que ajudam na edição dos blogs e dois professores responsáveis pela gestão dos blogs, totalizando assim 114 pessoas ouvidas durante a fase de coleta de dados.

\section{INSTRUMENTO DE COLETA DE DADOS}

Foram realizadas entrevistas semiestruturadas com amostras dos estudantes que utilizaram os blogs, visando a identificação dos pontos positivos e negativos da prática pedagógica adotada e a obtenção de um feedback dos alunos em relação às estratégias de utilização dos edublogs avaliados. De forma complementar às entrevistas com os alunos, buscou-se observar e realizar algumas reuniões com os atores envolvidos no uso e acesso aos blogs, visando colher opiniões e impressões sobre os resultados da utilização das ferramentas.

\section{ESTUDO DE CASO}

O estudo de caso realizado pode ser caracterizado como um estudo de caso múltiplo, por envolver a avaliação de mais de um blog. 


\section{BLOG "SIMPLIFICANDO A GOVERNANÇA DE TI"}

O blog Simplificando a governança de TI (LIMA, 2012) foi criado como desdobramento dos resultados descritos por Lima e Andriola (2013), tendo como seu objetivo principal a melhoria do processo de ensino-aprendizagem nas disciplinas da área de Governança de TI dos cursos de Bacharelado em Sistemas de Informação e Tecnologia em Redes de Computadores da Universidade Federal do Ceará. Entre os objetivos específicos desse blog, pode-se citar:

- Disseminação de informações sobre governança de TI na internet de forma geral;

- Ser o instrumento de publicação para trabalhos de pesquisa na área de governança de TI dos alunos dos cursos de sistemas de informação e redes de computadores da UFC;

- Ser fonte para pesquisa e aprendizado em governança de TI, para alunos de graduação de uma forma geral;

- Apresentar informações úteis para a formação de alunos de graduação e pósgraduação de uma forma geral.

O blog mostrado na Figura 1 pode receber contribuições de alunos e professores, bem como de profissionais da área de TI de forma geral. As postagens são utilizadas como fonte de pesquisa pelos alunos do campus da UFC em Quixadá-Ce. Tais contribuições são tratadas como objetos de aprendizagem no contexto das disciplinas de gestão de tecnologia da informação ofertadas nos cursos de sistemas de informação e redes de computadores. Apesar dos alunos ainda não estarem cadastrados para postar diretamente informações no blog avaliado (situação ideal), suas postagens são recebidas diretamente, avaliadas por um comitê de alunos e pelo professor, que mediam as postagens e somente depois de aprovadas, são revisadas e publicadas pelo professor editor do blog. Um aspecto importante a ressaltar é que a participação dos alunos interagindo com o blog faz parte dos critérios de avaliação das disciplinas que o utilizam como ferramenta. 
Figura 1 - Blog Simplificando a Governança de TI

Fonte: Elaboração própria.

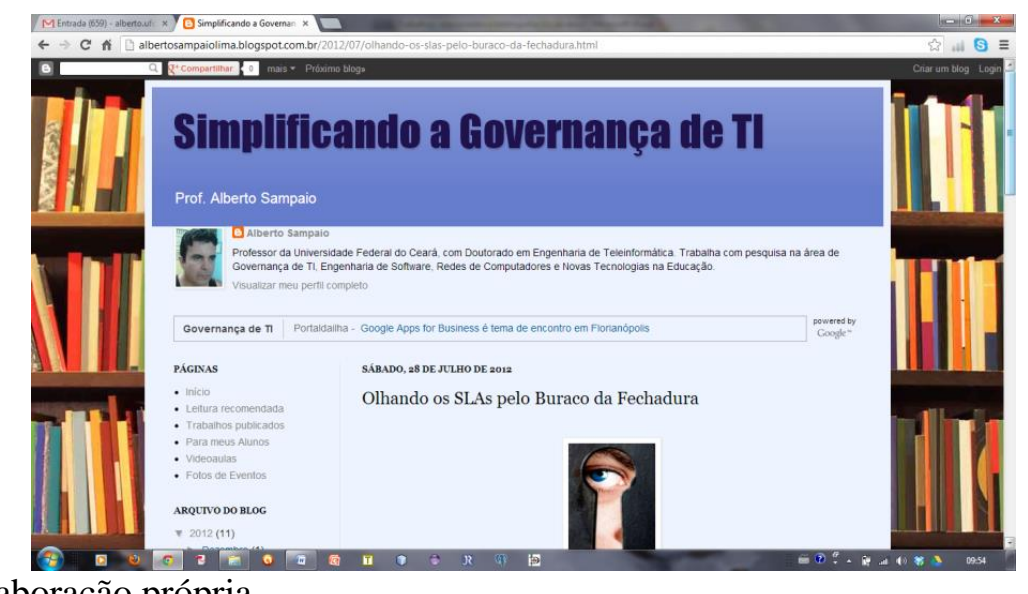

Segundo Garcia-Sabater et al. (2012), a utilização de um blog único centrado no processo ensino-aprendizagem facilita o trabalho do professor e é a forma mais utilizada, tendo se mostrado eficaz.

As disciplinas que utilizaram o blog como ferramenta fizeram uso dos textos postados relacionados ao tema governança de TI, realizando perguntas sobre esses textos. Visando melhorar a compreensão do aluno sobre os assuntos discutidos, ainda foram adicionados recursos de vídeos, imagens, etc. Regularmente, os professores mencionam em sala de aula e compartilham informações no Facebook sobre as novidades que são postadas no blog.

A partir de entrevista semiestruturada aplicada a um grupo de 51 alunos dos cursos de sistemas de informação e redes de computadores da UFC, resultados indicaram que a estratégia poderia ser utilizada de uma forma mais ampla, mas ainda associada ao processo de ensino-aprendizagem em um processo continuado.

Visando uma continuidade na formação dos alunos dos cursos de TI do Campus da UFC em Quixadá-Ce no tema, os artigos apresentados no II Workshop de Governança de Tecnologia da Informação do Sertão Central, evento promovido no campus da UFC em Quixadá no ano de 2013, no contexto das disciplinas de gestão da informação e dos sistemas de informação e gestão de tecnologia da informação e comunicação, foram disponibilizados em sua íntegra no blog, e os 10 melhores artigos, escolhidos por votação entre os alunos, foram convertidos em postagens e divulgados entre os alunos do campus via o grupo campus da UFC em Quixadá no Facebook.

As entrevistas realizadas com os alunos mostraram os seguintes pontos positivos obtidos a partir da utilização do blog no processo ensino-aprendizagem: 
- Incremento da motivação dos alunos para estudarem o assunto e buscarem certificação de mercado na área;

- Ampla comunicação sobre o tema com os demais alunos dos cursos de TI no campus;

- O uso do blog possibilitou aos alunos trabalharem no seu próprio ritmo, avançando nas atividades de acordo com o seu grau de aprendizagem real;

- Os alunos ficaram conscientes sobre suas deficiências em relação ao processo de escrita de artigos, postagens, e buscaram o conhecimento necessário para desenvolver essas habilidades;

- Melhoria nos resultados gerais dos alunos nas disciplinas que utilizam o recurso como ferramenta.

O blog é acessado periodicamente pelos alunos e tem algumas de suas notícias compartilhadas pelos professores e alunos via Facebook, como mostrado na Figura 2. Algumas atividades utilizando as informações disponíveis no blog são realizadas como trabalhos dentro e fora da sala de aula. A Figura 3 simboliza alguns alunos do curso de Sistemas de Informação da UFC pesquisando e acessando o blog em sala de aula, para solução de trabalho envolvendo o tema governança de TI.

Os pesquisadores observaram a falta de debate entre os alunos, a partir das postagens do blog, usando a própria ferramenta. Ainda existem muito poucos comentários a partir das postagens. Acredita-se que talvez exista algum receio por conta da mediação do professor nas atividades. Como desdobramento desse resultado, pretende-se propor um meio para incentivar os alunos a discutirem mais os temas durante suas próximas atividades em disciplinas utilizando o $b l o g$.

Em relação ao aprendizado, foi informado por $96 \%$ dos entrevistados (especificamente da amostra de usuários desse blog) que a utilização do blog simplificando a governança de TI contribuiu para seu aprendizado e na obtenção de melhores resultados na disciplina que foi suportada pelo mesmo. Os resultados ainda indicaram que esse mesmo percentual de alunos preferiam a disciplina com a estratégia de utilização de blogs em relação às disciplinas cursadas com estratégias pedagógicas convencionais. 
Figura 2 - Divulgação das informações do blog no Facebook

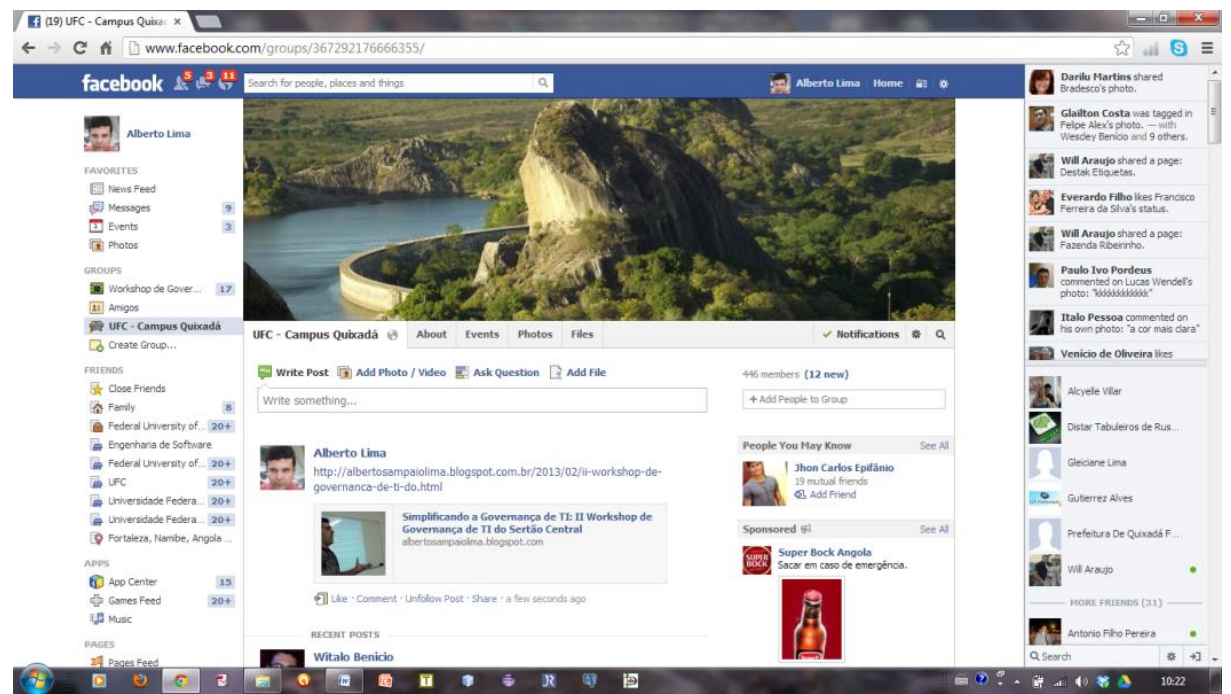

Fonte: Elaboração própria.

Figura 3 - Utilização de blog nas atividades em sala de aula

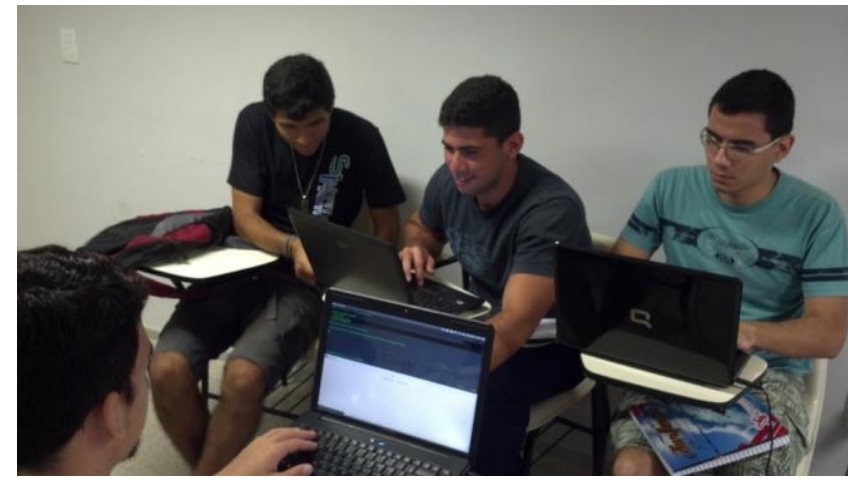

Fonte: Elaboração própria.

\title{
BLOG MARATHONCODE
}

De acordo com a Sociedade Brasileira de Computação (2013),

\begin{abstract}
A maratona de programação é um evento da Sociedade Brasileira de Computação (SBC) que existe desde o ano de 1996. Desde o ano de 2006 o evento vem sendo realizado em parceria com a Fundação Carlos Chagas. A Maratona nasceu das competições regionais classificatórias para as finais mundiais do concurso de programação da ACM, o ACM International Collegiate Programming Contest, e é parte da regional sul americana do concurso.
\end{abstract}

O público-alvo da maratona de programação consiste nos alunos de cursos de graduação e início de pós-graduação na área de computação e afins (Ciência da Computação, Engenharia de Computação, Sistemas de Informação, Matemática, etc.). A SBC (2013) cita que a competição promove nos alunos a criatividade, a capacidade de trabalho em equipe, a busca de novas soluções de software e a habilidade de resolver 
problemas sob pressão. Várias universidades do Brasil desenvolvem concursos locais para escolher os melhores times para participar da maratona de programação. Estes times competem na maratona (e, portanto, na regional sul americana), de onde os melhores serão selecionados para participar das finais mundiais do evento.

A capacidade de projeto e desenvolvimento de programas eficientes é uma das principais habilidades necessárias para o egresso de cursos de graduação na área de computação. Entretanto, o ensino de programação se constitui em uma das disciplinas com os maiores índices de reprovação de alunos nos cursos de graduação do campus da UFC em Quixadá, ensejando a discussão sobre possíveis formas pedagógicas inovadoras visando melhorar os resultados dos alunos.

Com o objetivo de tentar melhorar o aprendizado dos alunos nas disciplinas relacionadas às linguagens de programação nos cursos de graduação em Sistemas de Informação, Engenharia de Software e Redes de Computadores, professores pesquisadores do Campus da UFC em Quixadá desenvolveram um projeto de apoio à graduação, executado através de um grupo de estudos voltado à competição Maratona de Programação, iniciado no ano de 2009. No primeiro momento deste projeto, foi criada uma lista de discussão com o objetivo de absorver todas as informações oriundas durante o processo de aprendizagem. Infelizmente, a informação estava bastante espalhada e com poucas ligações entre si. Em um segundo momento, foi enfrentado o problema de organização da informação e interligação entre os temas desenvolvidos. Para resolver este problema foi criado um website ${ }^{4}$, para servir como uma memória das atividades e dos estudos que foram realizados. $\mathrm{O}$ objetivo principal do site era evitar o retrabalho no treinamento de novas equipes que futuramente participariam de outras edições da competição Maratona de Programação.

O blog Marathoncode (TAVARES, 2011) foi criado como consequência desse projeto de apoio à graduação. O objetivo geral da criação desse blog foi facilitar a comunicação e o processo ensino-aprendizagem entre os membros do grupo de estudos, professores e alunos do Campus. Os objetivos específicos eram de treinar alunos para a competição Maratona de Programação, aprofundar os conhecimentos de programação dos alunos; desenvolver a capacidade cognitiva dos alunos, entre outros. A Figura 4 ilustra uma das postagens do blog.

${ }^{4}$ Endereço do website: <https://sites.google.com/site/quixadamaratona/>. Acesso em: 03 jun. 2015. 
Figura 4 - Postagem no blog Marathoncode

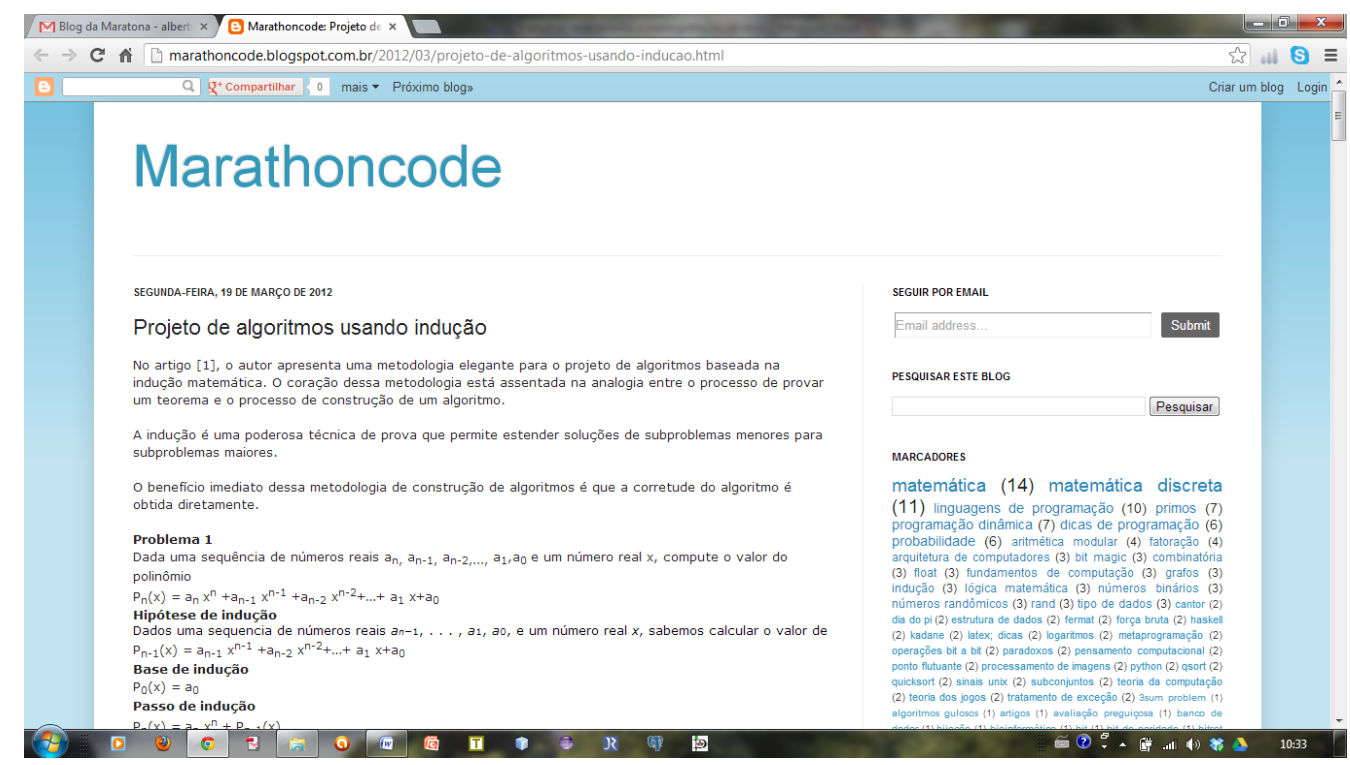

Fonte: Elaboração própria.

No início da utilização do blog pelos alunos e professores, foi gerado naturalmente um grande fluxo de informações: curiosidades, materiais de estudos, links para sites, informações e dúvidas.

A ferramenta do blog possui o objetivo de contribuir para três papéis educacionais importantes:

1. Agregar informações importantes;

2. Organizar as informações;

3. Interconectar as informações.

As postagens do blog consistem em uma exposição rica das reuniões de estudos desenvolvidas semanalmente pelo grupo de estudo para a competição Maratona de Programação. O blog permite a ligação (via links) das informações da aula com informações de outras fontes e ainda indica possíveis fontes mais aprofundadas de estudo e exercícios.

Os resultados das entrevistas realizadas especificamente com os usuários do blog indicaram que $98 \%$ dos alunos consideraram que o uso do blog contribuiu para um melhor resultado dos mesmos nas disciplinas de programação, bem como melhorou seu aprendizado. O mesmo percentual de alunos entrevistados demonstrou preferência pelas disciplinas que utilizaram o blog em sua estratégia pedagógica.

\section{BLOG PAPO DE ALUNO}


Um ponto importante no ensino superior consiste na formação do aluno como cidadão e profissional do mercado. O relato de experiências é uma estratégia importante e reconhecida no meio acadêmico, onde se pode identificar essa preferência pela existência de vários projetos de pesquisa e trabalhos acadêmicos que utilizam essa técnica em suas pesquisas.

Um dos grandes anseios identificados em conversas mantidas com os alunos dos cursos na área de computação do campus da UFC em Quixadá no ano de 2010, observados durante a experiência de um dos pesquisadores como coordenador do curso de Sistemas de Informação, consiste na necessidade do aluno obter um entendimento, mas sólido sobre o seu futuro profissional ao ingressar no mercado de trabalho ou continuar os seus estudos na academia, ingressando em programas de pós-graduação Lato e Strictu Senso.

Foi verificado que a ampla maioria dos alunos gostaria de ter informações compiladas sobre a aplicabilidade do que aprenderam durante seu período de formação para o mercado de trabalho, ou para uma possível continuidade nos estudos. Para isso, nada melhor do que proceder a uma leitura sobre a experiência de quem está vivendo ou vivenciou recentemente o papel de aluno.

O blog Papo de Aluno (TAVARES, 2011) é um espaço virtual onde os alunos e ex-alunos da UFC podem relatar suas experiências acadêmicas e profissionais, contribuindo para a formação dos demais colegas, proporcionando o acesso a um conjunto de informações importantes para os professores e alunos.

O objetivo geral do blog foi facilitar a troca de experiências entre alunos dos cursos de graduação na área de computação. As postagens de alunos e ex-alunos relatam experiências importantes sobre sua participação em programas governamentais tais como o Ciência sem Fronteiras, seu primeiro emprego na área, seu ingresso em programas de mestrado, entre outros tópicos de interesse para alunos e professores. Um professor atua como mediador e facilitador dessas atividades.

Os depoimentos apresentados no blog podem ser textuais ou em vídeo, como mostrado nas Figuras 5 e 6. 
Figura 5 - Depoimento de aluno em vídeo no blog Papo de Aluno

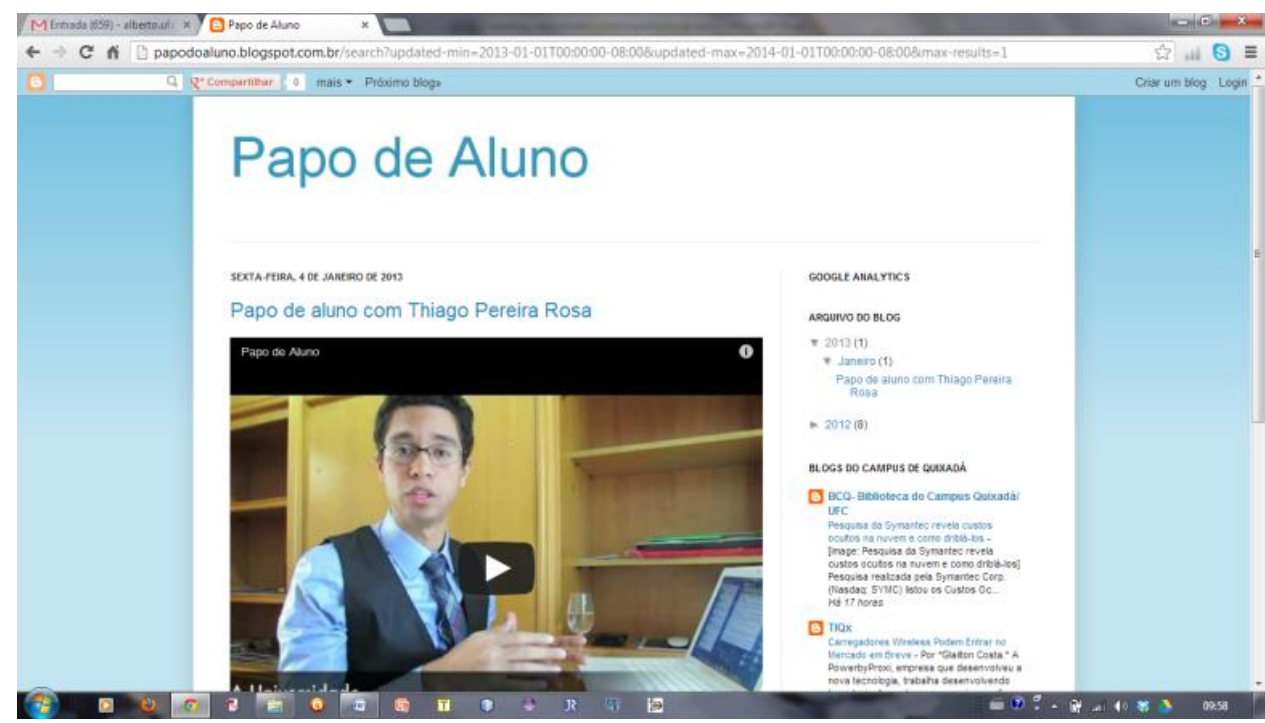

Fonte: Elaboração própria.

Figura 6 - Depoimento textual de aluno no blog Papo de Aluno

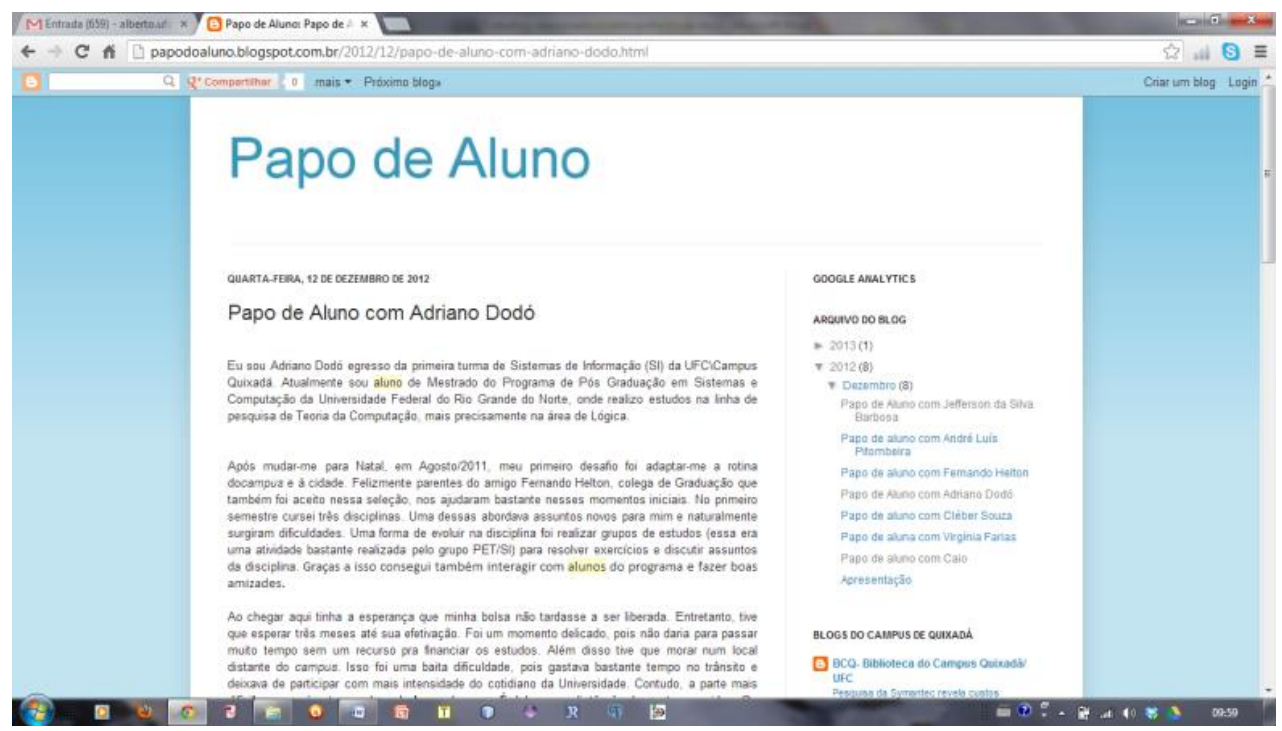

Fonte: Elaboração própria.

A organização das informações no blog possibilitou a realização de estudos comparativos, troca de experiências entre os alunos, comunicação entre os estudantes dentro e fora do país, entre outros benefícios identificados a partir dos resultados da criação do mesmo.

As repercussões dos resultados do blog Papo de Aluno (TAVARES, 2012) foram muito boas junto à comunidade acadêmica brasileira, tendo o mesmo sido elogiado em postagens de professores da lista da SBC. O blog, inicialmente criado para atender aos alunos dos cursos do campus da UFC em Quixadá, tem ganhado projeção a 
nível estadual e nacional e já possui a participação de relatos de alunos do curso de Ciência da Computação da UFC em Fortaleza.

\section{ANÁLISE E DISCUSSÃO DOS RESULTADOS}

A partir das entrevistas e conversas pessoais realizadas com os alunos que utilizam regularmente os três blogs avaliados neste estudo, verificou-se que o grau de satisfação dos mesmos aumentou significativamente a partir da utilização dos blogs em suas atividades rotineiras. Mais de $90 \%$ dos estudantes entrevistados nas avaliações dos três blogs confirmaram essa informação em suas entrevistas $(\mathrm{n}=103)$. A totalidade dos 114 alunos respondentes, usuários dos três blogs avaliados achou válida a utilização de blogs como instrumento facilitador do processo de aprendizagem, que os blogs fornecem uma maior autonomia ao aluno no controle do seu aprendizado, que estavam construindo conhecimento enquanto utilizando os blogs. Em relação a pergunta sobre se o blog poderia ser considerado um instrumento de comunicação sobre o assunto, ligando alunos e professores, 94\% do total dos respondentes $(n=107)$ responderam com assertivas positivas, enquanto $4 \%$ dos respondentes não responderam $(n=4)$ e $2 \%$ se manifestaram de forma negativa ou indiferente $(n=3)$.

Outro aspecto a ser ressaltado consiste em que a quase totalidade dos alunos usuários do blog Simplificando a Governança de TI (98\% ou n = 50) consideraram que, em termos de aprendizado, a adoção de trabalhos abordando resenhas sobre artigos publicados em anais de congressos e periódicos da área proporcionou um maior aprendizado que o estudo para uma prova tradicional. Entre as respostas dos alunos entrevistados sobre como o blog MarathonCode ajudou no estudo para a maratona de programação, destacamos as seguintes:

- "Auxiliando com exemplos práticos, e com códigos até então desconhecidos";

- "No blog podemos encontrar vários exemplos de código, bem como várias dicas sobre como desenvolver algoritmos rápidos e eficientes";

- "Pude aprender assuntos novos que até então não tinha conhecimento. É uma ótima fonte de conhecimento";

- "O blog tem uma grande quantidade de matérias que ajuda na criação de soluções para vários problemas";

- "Não somente para a maratona, o blog ainda me dá dicas de como posso resolver alguns problemas, ajudando a desenvolver o meu raciocínio lógico".

A solução de problemas de governança de TI obtidos a partir de provas de concursos públicos motivou bastante os alunos no desenvolvimento de atividades por 
meio do blog Simplificando a Governança de TI, no qual todos os entrevistados usuários do blog $(\mathrm{n}=51)$ declararam se sentirem motivados a trabalhar na solução desses problemas. A solução de problemas obtidos a partir de provas de certificação de mercado para os guias Information Technology Infrastructure Library (ITIL) e Control Objectives for Information and related Technology (COBIT) também foram citados como sendo fatores motivadores para os alunos quando utilizando o blog em suas atividades. Em relação à pergunta sobre se existe motivação dos alunos para a leitura e realização de atividades utilizando o blog, todos os entrevistados $(\mathrm{n}=114)$ responderam sim.

A facilidade em poder comentar as postagens e informações publicadas no próprio blog e através das redes sociais foi exaltada pelos entrevistados na avaliação dos três blogs. Um ponto importante destacado pelos alunos foi o interesse em ler e comentar os trabalhos uns dos outros, como no caso das publicações do workshop de governança de TI e nas postagens do blog Marathoncode.

Outro fator importante citado pelos entrevistados foi a participação ativa dos membros/leitores e escritores, a interdisciplinaridade de assuntos abordados nos blogs, a linguagem escrita de fácil compreensão, o aprofundamento do assunto visto em sala de aula, o incremento e fortalecimento do pensamento e/ou opinião sobre os assuntos abordados.

A ampla difusão do conhecimento foi outro fator positivo citado pelos entrevistados, diferenciando os blogs das listas de discussão, que mantém conteúdo restrito aos participantes.

A partir dos resultados obtidos nas entrevistas realizadas com alunos que cursaram disciplinas onde os edublogs foram utilizados efetivamente no processo de ensino e aprendizagem e com os professores que ministraram essas disciplinas, foi verificado que mais de $80 \%$ dos entrevistados responderam positivamente às perguntas, como é mostrado na Tabela 1.

Esse fato, associado ao crescimento percentual da nota média dos alunos nas disciplinas avaliadas (comparadas com médias anteriores), mostram indicativos de que houve uma melhoria no aprendizado a partir da utilização dos edublogs avaliados no estudo de caso. 
Tabela 1 - Resultados da utilização de edublogs como ferramenta de apoio em disciplinas de graduação

\begin{tabular}{|l|c|c|c|c|}
\hline \multicolumn{1}{|c|}{ Edublog } & $\begin{array}{c}\text { Disciplina Ligada } \\
\text { ao Uso do Blog }\end{array}$ & $\begin{array}{c}\text { Houve Contribuição } \\
\text { para o aprendizado na } \\
\text { visão do aluno }\end{array}$ & $\begin{array}{c}\text { Houve Contribuição } \\
\text { para o aprendizado } \\
\text { na visão do professor }\end{array}$ & $\begin{array}{c}\text { Incremento nos } \\
\text { resultados médios de } \\
\text { notas na disciplina }\end{array}$ \\
\hline $\begin{array}{l}\text { Simplificando a } \\
\text { Governança de TI }\end{array}$ & $\begin{array}{c}\text { Gestão da } \\
\text { Informação e dos } \\
\text { Sistemas de } \\
\text { Informação }\end{array}$ & $86 \%$ & $100 \%$ & $13 \%$ \\
\hline $\begin{array}{l}\text { Simplificando a } \\
\text { Governança de TI }\end{array}$ & $\begin{array}{c}\text { Governança } \\
\text { Estratégica de TI }\end{array}$ & $91 \%$ & $100 \%$ & $20 \%$ \\
\hline $\begin{array}{l}\text { Simplificando a } \\
\text { Governança de TI }\end{array}$ & $\begin{array}{c}\text { Gestão de } \\
\text { tecnologia da } \\
\text { informação e } \\
\text { comunicação }\end{array}$ & $85 \%$ & $100 \%$ & $12 \%$ \\
\hline Marathoncode & $\begin{array}{c}\text { Fundamentos de } \\
\text { programação }\end{array}$ & $98 \%$ & $100 \%$ & $12 \%$ \\
\hline Marathoncode & $\begin{array}{c}\text { Linguagens de } \\
\text { programação }\end{array}$ & $92 \%$ & $100 \%$ & $16 \%$ \\
\hline
\end{tabular}

Fonte: Elaboração própria.

Os alunos usuários do blog Marathoncode destacaram os seguintes aspectos positivos relacionados ao processo ensino-aprendizagem a partir da utilização do blog:

- O retorno dos comentários de cada artigo sobre diferentes assuntos;

- Grande quantidade de conteúdo disponibilizado no blog, facilitando a busca de informações;

- Construção de novos conhecimentos que não são aprendidos em sala de aula;

- Referencial teórico (código) associado à sua utilização prática.

Entre os aspectos negativos relatados pelos entrevistados (dos três blogs) para a utilização dos blogs no processo ensino-aprendizagem, pode-se citar:

- Dificuldade na comunicação entre os usuários em certas ocasiões;

- Falta de conhecimento sobre determinados assuntos;

- Dificuldades para emissão de comentários;

- Dificuldades para o relacionamento entre a teoria e alguns comentários.

A maioria dos alunos entrevistados não apresentou reclamação sobre o estilo de informação apresentado nos blogs avaliados ( $\mathrm{n}=112$ ou 98\%), mas é importante se ressaltar as dificuldades relatadas por alguns alunos: "Quando a informação a ser transmitida for muito longa, ela se torna cansativa, então, quando for nesses casos, quebrar o texto, deixando ele com mais parágrafos, seria uma boa”; "A princípio não me dou muito bem com o estilo como as informações são apresentadas no blog ...”. 


\section{CONCLUSÕES E PERSPECTIVAS}

O aprendizado como construção de significados tem obtido resultados recentes promissores, a partir da utilização das TICs como ferramentas de suporte ao processo de ensino e aprendizagem. O construtivismo (FERRACIOLI, 1999) tem sido utilizado como base para a construção de abordagens que utilizam ferramentas tecnológicas importantes, tais como os blogs que foram avaliados nesta pesquisa. Busca-se a visão do aluno como um sujeito ativo, autônomo, que pouco a pouco pode conhecer os seus próprios processos cognitivos (estilos de aprendizagem). A partir do princípio de se buscar não apenas a aquisição de conhecimentos, mas a construção desse conhecimento através do uso da experiência para se compreender e modelar o novo, foi identificado que os edublogs podem ser utilizados no processo de aprender a aprender.

Foi observado a existência de esquemas de assimilação adequados no nível de instrução que foi apoiado pelos blogs nas disciplinas. Observou-se ainda durante o estudo realizado a existência de uma tomada de consciência por parte dos alunos que utilizaram os blogs como ferramentas de apoio nas disciplinas cursadas, o que segundo Ferracioli (1999), seria a passagem do porque para o como, com a construção dos conceitos abordados na instrução.

Esta pesquisa apresentou um estudo sobre a utilização de edublogs como estratégia para fornecer suporte aos professores de ensino superior da área de computação no processo de ensino e aprendizagem. Foi realizada uma revisão bibliográfica sobre a utilização de novas tecnologias, onde foi identificado que somente a utilização da TIC pode não trazer mudanças significativas no processo tradicional de ensino. O professor deve buscar criar um diferencial através de uma abordagem construtivista para a utilização de novas tecnologias no processo de ensino e aprendizagem. A utilização de edublogs por professores da Universidade Federal do Ceará como ferramenta de suporte ao processo de ensino e aprendizagem foi avaliada e considerada como uma possível alternativa para melhorar os resultados de disciplinas nos cursos superiores na área de computação.

Os resultados obtidos a partir dos estudos realizados ainda indicaram que os blogs possuem enorme potencial para promover a socialização do conhecimento e a interação entre os alunos. Além disso, pode-se incrementar a interação entre professores e alunos, através de atividades colaborativas que envolvam desde a disponibilização de material até a análise de artigos e temas relevantes ao aprendizado em uma disciplina. A 
grande maioria dos entrevistados preferiu cursar disciplinas com estratégias pedagógicas que incluíssem a utilização dos blogs como ferramenta de suporte em relação a disciplinas com estratégias pedagógicas convencionais. Os entrevistados ainda afirmaram que houve melhoria no seu aprendizado a partir da utilização dos edublogs, como foi mostrado na seção de análise dos resultados.

Devido ao fato deste trabalho ter avaliado somente três $b \log s$, cada um com suas finalidades e objetivos distintos, pode existir alguma dificuldade na generalização dos resultados apresentados para disciplinas de outras áreas de conhecimento. Entretanto, apesar de preliminares, os resultados obtidos indicam que a utilização de blogs como ferramenta pedagógica pode contribuir muito para a atuação dos professores do ensino superior na área de computação ao conduzirem suas disciplinas.

Como trabalhos futuros, pretende-se avaliar a utilização dos edublogs como ferramenta de suporte ao processo de ensino e aprendizagem em disciplinas de cursos de graduação de outras áreas de conhecimento.

\title{
USING EDUBLOGS TO IMPROVE TEACHING AND LEARNING IN COMPUTER AREA UNDERGRADUATE COURSES
}

\begin{abstract}
The use of blogs as pedagogical tools in teaching-learning process is actual and very discussed by education researchers. this work presents a study about using blogs as mediators in teaching and learning process in computing graduation. We evaluated three blogs used by the students of federal university of ceara (ufc). We evaluated the problems and the success scenarios where the blog utilization increased student motivation, improving learning results and generating better evaluation indexes related to teaching activities by professors.
\end{abstract}

KEY WORDS: Edublogs. Teaching-learning process. Pedagogical practices.

\section{REFERÊNCIAS}

ALZINA, R. B. Metodología de la investigación educativa. Madrid: Editorial la Muralla, 2004.

ANDERSON, J. R. Cognitive psychology and its implications. New York: Freeman, 1995.

ANDRIOLA, W. B. Avaliação do aprendizado discente: estudo com professores de Escolas Públicas. Educar em Revista, Curitiba, n.46, p.141-158, 2012. 
Avaliação da aprendizagem: conceitos, dados, problemas e perspectivas.

Psicologia Argumento, Curitiba, v.22, n.39, p.45-55, 2004.

Cuidados na avaliação da aprendizagem: algumas reflexões. In: Mc DONALD, B. C. (Org.). Esboços em avaliação educacional. Fortaleza: Ed. da UFC, 2003. p.157168.

BARRO, M. R.; QUEIROZ, S. L. Blogs no ensino de química: utilização e avaliação da aceitação em disciplina de comunicação científica. Revista Brasileira de Informática na Educação, Porto Alegre, v.20, n.2, p.03-16, 2012.

BENTO, M. C. M.; MIGUEL, G. C. P.; ALEXANDRE, J. A. A. Formação continuada de pedagogos por meio do blog. ECCOM, [S.1.], v.3, n.5, p.51-68, 2012. Disponível em: <http://publicacoes.fatea.br/index.php/eccom/article/viewFile/480/327>. Acesso em: 03 set. 2015.

BORBA, G. L.; THOMAZI, A. R. G. Uso das TIC em escolas de computação: relações entre a tecnologia, o educador e o educando, no processo de ensino-aprendizagem.

Revista Educação e Tecnologia, Curitiba, n.12, p.03-20, 2012.

DE BARROS, C. M. F. A distância das TIC`s com a formação docente: observações da inclusão e uso de objetos de aprendizagem no ensino técnico de edificações. In: SIMPÓSIO INTERNACIONAL DE EDUCAÇÃO À DISTÂNCIA, 1.; ENCONTRO DE PESQUISADORES EM EDUCAÇÃO A DISTÂNCIA, 1., 2012, São Carlos. Anais... São Carlos: UFSCAR, 2012. p.01-13. Disponível em: <http://sistemas3.sead.ufscar.br/ojs1/index.php/sied/issue/view/1>. Acesso em: 03 set. 2015 .

FERRACIOLI, L. Aprendizagem, desenvolvimento e conhecimento na obra de Jean Piaget: uma análise do processo de ensino-aprendizagem em Ciências. Revista Brasileira de Estudos Pedagógicos, Brasília, v.80, n.194, p.5-18, 1999.

GARCIA-SABATER, J. J. et al. Edublogs en docencia de postgrado: ejecución y evaluación. In: INTERNATIONAL CONFERENCE ON INDUSTRIAL ENGINEERING AND INDUSTRIAL MANAGEMENT, 6.; CONGRESO DE INGENIERÍA DE ORGANIZACIÓN, 16., 2012, Vigo. Anais... [S.1: s.n.], 2012. Disponível em:

<http://www.adingor.es/congresos/web/uploads/cio/cio2012/SP_05_Innovacion_docent e/1320-1327.pdf>. Acesso em: 03 set. 2015.

GIL, A. C. Métodos e técnicas da pesquisa social. São Paulo: Atlas, 1999.

HOWE, M. J. A. La capacidad de aprender: la adquisición y desarrollo de habilidades. Madrid: Alianza Editorial, 1999.

A teacher's guide to the psychology of learning. Oxford: Blackwell, 1985.

LEE, H. B. Investigación del comportamiento: métodos de investigación en ciencias sociales. México: McGraw Hill, 2002. 
LIMA, A. S. Blog simplificando a governança de TI. 2012. Disponível em:

<albertosampaiolima.blogspot.com.br>. Acesso em: 03 set. 2015.

LIMA, A. S.; ANDRIOLA, W. B. Using innovative pedagogical practices in disciplines of engineering and computing graduation in Brazil. In: ANNUAL GLOBAL

ENGINEERING EDUCATION CONFERENCE, 4., 2013, Berlin. Anais... [S.1]: IEEE, 2013. p.394-399. Disponível em:

<http://ieeexplore.ieee.org/stamp/stamp.jsp?tp=\&arnumber=6530135>. Acesso em: 03 set. 2015.

LINS, H. A. M. Os blogs, as novas tecnologias e as práticas pedagógica: questões sócioculturais, políticas e de formação docente. Instrumento: Revista de Estudo e Pesquisa em Educação, Juiz de Fora, v.13, n.2, p.35-42, 2011.

LINS, S. D. O modelo cognitivista de ensino-aprendizagem. Cadernos de Educação, Fortaleza, v.24, p.46-56, 2000.

MARQUES, D. V. A.; MÜLLER, F. Experiências com blog na pesquisa e na formação inicial de professoras da educação infantil. ETD - Educ. Tem. Dig., [S.1.], v.14, n.1, p.43-61, 2012. Disponível em:

<http://www.ssoar.info/ssoar/bitstream/handle/document/31273/ssoar-etd-2012-1marques_et_al-experiencias_com_blog_na_pesquisa.pdf?sequence $=1>$. Acesso em: 03 set. 2015.

MAZOCATTO, A. P. F.; KRUG, H. N. Algumas discussões postadas no Blog/GEPEF/UFSM relacionadas à formação continuada de professores de educação física. In: SIMPÓSIO INTERNACIONAL DE EDUCAÇÃO À DISTÂNCIA, 1.; ENCONTRO DE PESQUISADORES EM EDUCAÇÃO A DISTÂNCIA, 1., 2012, São Carlos. Anais... São Carlos: UFSCAR, 2012. p.01-10. Disponível em:

<http://sistemas3.sead.ufscar.br/ojs1/index.php/sied/issue/view/1>. Acesso em: 03 set. 2015.

MISHNE, J. M. A curva da aprendizagem: elevando a competência acadêmica e social. Porto Alegre: Artmed, 1999.

MOLINS, L.; RAABE, A. Novas tecnologias na educação: transformações da prática pedagógica no discurso do professor. Revista Acta Scientiarum, Maringá, v.34, n.2, p.249-259, 2012.

PÉREZ, M. P. El Blog como instrumento de enseñanza-aprendizaje de idiomas. Revista Digital del Centro del Profesorado Cuevas-Olula, Almeria, v.3, n.9, p.26-36, 2012.

POZO, J. L. Teorias cognitivas de aprendizagem. Porto Alegre: Artmed, 2002.

PUENTES FERRERAS, A. Cognición y aprendizaje: fundamentos psicológicos. Madrid: Ediciones Psicología Pirámide, 1998.

RAMOS, E. A. Processo de ensino. Cadernos de Educação, Fortaleza, v.24, p.57-70, 2000. 

1999.

Aprendizagem humana. Cadernos de Educação, Fortaleza, v.23, p.37-49,

SÁEZ, J. M. La práctica pedagógica de las tecnologías de la información y la comunicación y su relación con los enfoques constructivistas. REICE: Revista Iberoamericana sobre Calidad, Eficacia y Cambio en Educación, Madrid, v.10, n.1, p.58-73, 2012.

SILVA, A. P. A.; SILVA, C. R. A.; MAIOCHI, K. F. S. Ações interativas e integrativas no ambiente escolar mediadas pelo uso de blog nas séries de alfabetização. Tear:

Revista de Educação Ciência e Tecnologia, Canoas, v.1, n.1, 2012.

SOCIEDADE BRASILEIRA DE COMPUTAÇÃO [SBC]. Maratona de programação. Porto Alegre, 2013. Disponível em:

$<$ http://www.sbc.org.br/index.php?option=com_content\&view=category\&layout=blog $\&$ id=303\&Itemid=180>. Acesso em: 03 set. 2015.

STERNBERG, R. J.; GRIGORENKO, E. L. Inteligência plena: ensinando e incentivando a aprendizagem e a realização dos alunos. Porto Alegre: Artmed, 2003.

TASSIGNY, M. M. et al. Blog: ferramenta estratégica de comunicação organizacional. Revista Administrativa da UFSM, Santa Maria (RS), v.5, n.2, p.262-276, 2012.

TAVARES, W. A. Blog papo de aluno. 2012. Disponível em:

<http://http://papodoaluno.blogspot.com.br>. Acesso em: 03 set. 2015.

Blog Marathoncode. 2011. Disponível em:

<http://marathoncode.blogspot.com.br/>. Acesso em: 03 set. 2015.

WILLIAMS, J. B.; JACOBS, J. Exploring the use of blogs as learning spaces in the higher education sector. Australasian Journal of Educational Technology, Wagga Wagga, v.20, n.2, p.232-247, 2012.

YANG, S.-H. Using blogs to enhance critical reflection and community of practice. Journal of Educational Technology \& Society, [S.1.], v.12, n.2, p.11-21, 2009. 